\title{
Failure of intravitreal bevacizumab in the treatment of choroidal metastasis
}

A Maudgil, KS Sears, PA Rundle, IG Rennie and SM Salvi

\begin{abstract}
Background Metastasis to choroid is the most common intraocular malignancy, arising most frequently from carcinoma of breast in women and lung in men. Recent case reports have described successful use of intravitreal bevacizumab to achieve local control of such tumours.

Materials and methods Five cases of choroidal metastases from varying primaries: breast, lung, and colon were treated with intravitreal bevacizumab, and tumour response observed and documented with serial photographs and B-scans.

Results Four of the five tumours were seen to progress despite intravitreal bevacizumab treatment.

Conclusions Intravitreal bevacizumab as the primary treatment of choroidal metastases is not recommended and should not delay more effective alternative treatments.
\end{abstract}

Eye (2015) 29, 707-711; doi:10.1038/eye.2015.21; published online 13 March 2015

\section{Introduction}

Choroidal metastases are commonly seen in ocular oncology services, and although they represent disseminated, and usually advanced disease, treatment is desirable to locally control growth and hopefully preserve vision. Current options include photodynamic therapy (PDT), radiation plaque brachytherapy, external beam radiation therapy (EBRT), and systemic chemotherapy. ${ }^{1}$ Recent literature reports intraocular tumour regression using intravitreal bevacizumab, ${ }^{2-9}$ a selective VEGFA inhibitor, presently licensed as an intravenous chemotherapeutic agent in several advanced cancers, including metastatic colorectal carcinoma. ${ }^{10}$ This report describes experience of treating five patients with choroidal metastasis with intravitreal bevacizumab $1.25 \mathrm{mg} / 0.05 \mathrm{ml}$ via pars plana approach. Visual acuity data is summarized in Table 1.

\section{Case reports}

Case 1

An 80-year-old male treated 6 months previously with hemicolectomy and partial hepatectomy for metastatic, moderately differentiated adenocarcinoma of caecum presented with reduced vision in his right eye. A solitary choroidal metastasis was noted (Figure 1a) and treated with a single intravitreal injection of bevacizumab. Three weeks later, the lesion had progressed with exudative retinal detachment (Figure 1b). Systemic chemotherapy was commenced and dramatic regression occurred within 2 months.

\section{Case 2}

A 61-year-old lady with a history of adenocarcinoma of left lower lung lobe 4 years previously, presented with a 4-month history of decreased vision and photopsiae in the right eye. Examination revealed choroidal metastasis extending superiorly from the optic disc (Figure 1c). Three intravitreal bevacizumab injections were given in the right eye at monthly intervals. Follow-up 1 month later revealed growth with extraocular extension (Figure 1d) requiring EBRT.

Case 3

A 43-year-old lady presented with a 3-month history of reduced vision in the right eye. Six years previously, she had been treated for breast carcinoma with wide local excision, axillary clearance, and chemoradiotherapy. Recently bone, lung, and lymph node
Sheffield Ocular Oncology Service, Department of Ophthalmology, Royal Hallamshire Hospital, Sheffield, UK

Correspondence: A Maudgil, Sheffield Ocular Oncology Service, Department of Ophthalmology, Royal Hallamshire Hospital, Glossop Road, A-Floor Sheffield S10 2JF, UK Tel: +44 (0)114 271 3829; Fax: +44 (0)114 2713747. E-mail: anumaudgil@ gmail.com

Received: 29 October 2014 Accepted in revised form: 19 January 2015 Published online: 13 March 2015 
Table 1 Visual acuity (VA) data for patients before and after treatment with intravitreal bevacizumab

\begin{tabular}{lcc}
\hline & VA before treatment & VA after treatment \\
\hline Case 1 & $6 / 60$ & $\mathrm{HM}$ \\
Case 2 & $6 / 18$ & $6 / 36$ \\
Case 3 & $6 / 18-1$ & $6 / 60$ \\
Case 4 & $6 / 18$ & $6 / 60$ \\
Case 5 & $\mathrm{CF}$ & $\mathrm{HM}$ \\
\hline
\end{tabular}

metastases were treated with hormone replacement injections. Examination revealed right choroidal metastasis. PDT was given ( 3 spots, $7.2 \mathrm{~mm}, 83 \mathrm{~s}$, $600 \mathrm{~mW} / \mathrm{cm}^{2}$ ) with good tumour regression at 6 weeks. Residual tissue was active 2 months later (Figure 1e). Three injections of intravitreal bevacizumab were given at monthly intervals. Despite this, the lesion grew (Figure 1f) and was then successfully treated with EBRT.



Figure 1 Case reports. (a) Case 1: Colour photograph of right eye showing choroidal metastasis from caecal adenocarcinoma. (b) Case 1: Optos widefield photograph showing exudative retinal detachment following massive growth of choroidal metastasis after single Avastin injection. (c) Case 2: Optos widefield photograph of choroidal metastasis emanating from superior aspect of optic disc from primary adenocarcinoma of lung. (d) Case 2: Optos widefield photograph demonstrating growth of choroidal metastasis 1 month after 3 intravitreal bevacizumab injections. (e) Case 3: Colour photograph showing tumour recurrence at superior edge 2 months after PDT. (f) Case 3: Colour photograph of superior fundus showing massive growth of choroidal metastasis after the course of injections. 

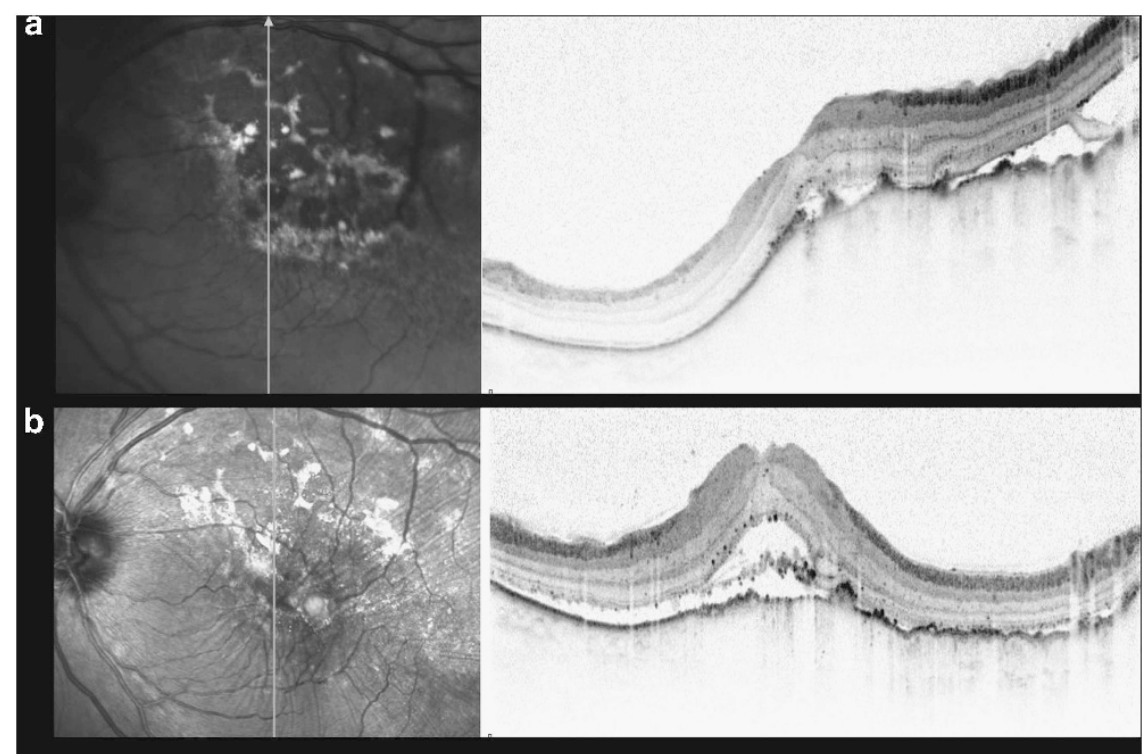

c

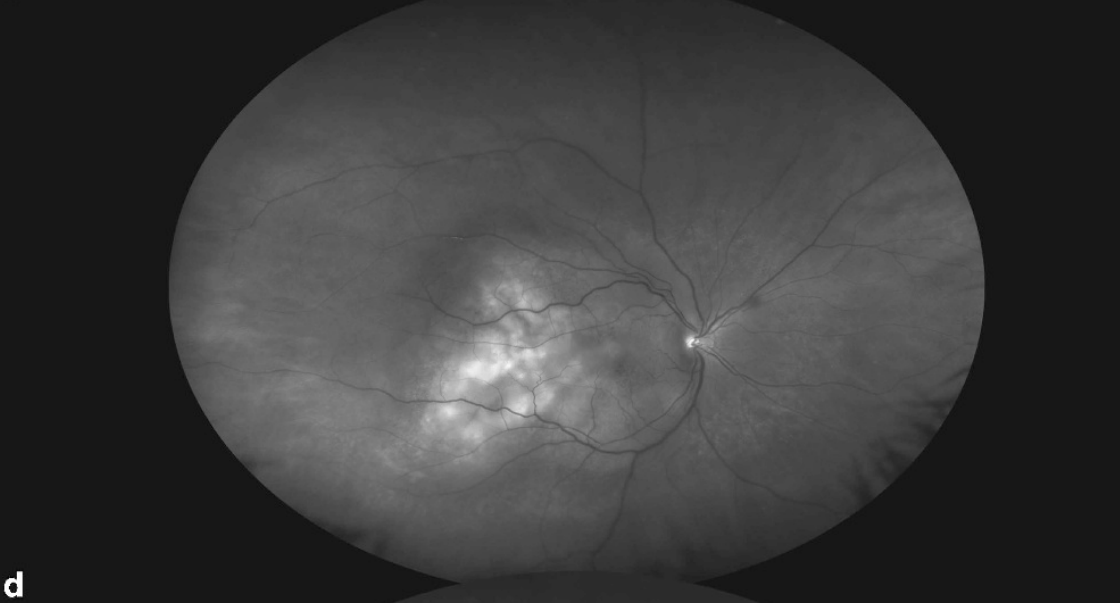

d

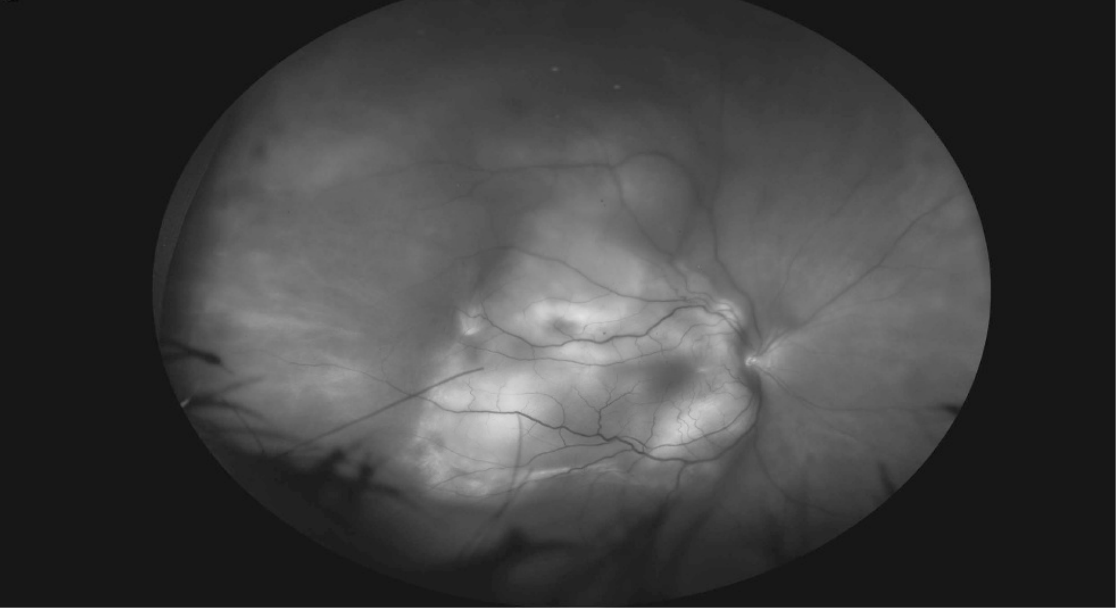

Figure 2 Case reports. (a) Case 4: Spectral OCT image through choroidal metastasis showing typical irregular surface, not responded to radiotherapy. (b) Case 4: Spectral OCT image through regressed choroidal metastasis after three intravitreal bevacizumab injections. (c) Case 5: Optos widefield photograph showing central choroidal metastasis from adenocarcinoma of caecum. (d) Case 5. Optos widefield photograph showing growth of choroidal metastasis after two intravitreal bevacizumab injections. 


\section{Case 4}

A 62-year-old lady, with a history of breast carcinoma treated 4 years previously with local excision and chemoradiotherapy, presented with episodic visual distortion. Examination revealed posterior pole choroidal metastasis and iris metastasis. Further chemotherapy induced regression over 6 months. Edge recurrence occurred 10 months later, which showed no immediate response to EBRT (Figure 2a). Three Avastin injections were prescribed at monthly intervals. At review a month later, the lesion appeared regressed (Figure 2b).

\section{Case 5}

A 57-year-old lady with an 18-month history of metastatic adenocarcinoma of the caecum presented with decreased vision over 2 months. She had been treated with a combination of chemotherapy and bowel and liver resection. Lung and joints were involved. Examination revealed a large macular choroidal metastasis (Figure 2c). Three intravitreal bevacizumab injections were planned monthly, but review after the second revealed growth (Figure 2d). A third injection was given, with simultaneous referral for EBRT. This patient is now deceased.

\section{Discussion}

Published work on the use of intravitreal bevacizumab in the treatment of choroidal disorders is prolific, and recent success in the treatment of choroidal metastasis is reported with tumour regression. ${ }^{2-9}$ Our outcomes in two cases of adenocarcinoma of caecum, one breast carcinoma, and one adenocarcinoma of lung do not replicate this finding. Difference in pathologies do not explain this, as good effects have been described treating metastases from the same primaries: colon, ${ }^{4}$ breast, $^{2,5,8}$ and lung. ${ }^{6}$ One case, a breast metastasis, who had undergone EBRT in the previous 4 months with no immediate response, did regress after intravitreal bevacizumab. It is debatable whether this represented a delayed response to EBRT or was stimulated by the course of bevacizumab injections.

We used bevacizumab $1.25 \mathrm{mg}$ in $0.05 \mathrm{ml}$, prepared from a vial commercially available for intravitreal use (Avastin). Previous reports have used bevacizumab $2.5 \mathrm{mg}^{3,5,6,9}$ and others $4 \mathrm{mg}{ }^{2,4}$ The most recent cohort published $^{7}$ used bevacizumab $1.25 \mathrm{mg}$ and report regression in 3 cases with comparable pathologies.

Lin et al ${ }^{4}$ postulated that exudation could hinder the drug from reaching tumour in one eye with progressed disease. This could limit the potential efficacy of intravitreal bevacizumab in this condition, as most choroidal metastases are associated with significant exudation. OCT findings revealed that bevacizumab did not consistently reduce subretinal fluid, which is perhaps surprising given its known effects in exudative agerelated macular degeneration and diabetic maculopathy. Of relevance, may be the consideration that in choroidal metastatic lesions, the choriocapillaris and Bruch's membrane are intact, and this may hinder the passage of the bevacizumab molecule through the retina, as compared with diabetes and age-related macular degeneration where RPE and the blood-retinal barrier are compromised. ${ }^{11,12}$

If effective, intravitreal bevacizumab undoubtedly represents a convenient, well-tolerated local treatment for choroidal metastases. However, these results do not support the use of $1.25 \mathrm{mg} / 0.05 \mathrm{ml}$ bevacizumab injections as the primary treatment for choroidal metastasis. Further work is required to define which cases may benefit from treatment and at which dose.

\section{Summary}

What was known before

- Intravitreal bevacizumab is a useful treatment for a number of choroidal disorders.

- Previous work has demonstrated a potential role for intravitreal bevacizumab in the treatment of choroidal metastases in a small number of cases.

What this study adds

- This study of five cases is the largest published to date on the use of intravitreal bevacizumab in the treatment of choroidal metastases.

- Previous findings on the success of intravitreal bevacizumab in the treatment of choroidal metastases are not replicated.

- Although there may be a role of intravitreal bevacizumab as a adjuvant treatment in choroidal metastasis, its use as a primary treatment is not recommended.

\section{Conflict of interest}

The authors declare no conflict of interest.

\section{References}

1 Chen CJ, McCoy AN, Brahmer J, Handa JT. Emerging treatments for choroidal metastases. Surv Ophthalmol 2011; 56(6): 511-521.

2 Amselem L, Cervera E, Díaz-Llopis M, Montero J, Garcia-Pous M, Udaondo P et al. Intravitreal bevacizumab (Avastin) for choroidal metastasis secondary to breast carcinoma: short-term follow-up. Eye (Lond) 2007; 21(4): 566-567.

3 Kim SW, Kim MJ, Huh K, Oh J. Complete regression of choroidal metastasis secondary to non-small-cell lung cancer 
with intravitreal bevacizumab and oral erlotinib combination therapy. Ophthalmologica 2009; 223(6): 411-413.

4 Lin CJ, Li KH, Hwang JF, Chen SN. The effect of intravitreal bevacizumab treatment on choroidal metastasis of colon adenocarcinoma-case report. Eye (Lond) 2010; 24(6): 1102-1103.

5 Mansour AM, Alameddine R. Intravitreal bevacizumab for consecutive multiple choroidal breast metastatic lesions. BMJ Case Rep 2012; doi:10.1136/bcr.03.2012.6124.

6 Lai CL, Fan KS, Lee YH, Chen HC, Fan WH. Intravitreal administration of bevacizumab in the treatment of choroidal metastasis in a patient with erlotinib-failed pulmonary adenocarcinoma. Lung Cancer 2012; 76(3): 496-498.

7 Zhou Q, Liang J, Lu H. Intravitreal bevacizumab for ocular metastasis of multiple myeloma. Optom Vis Sci 2013; 90(9): 236-240.

8 Fenicia V, Abdolrahimzadeh S, Mannino G, Verrilli S, Balestrieri M, Recupero SM. Intravitreal bevacizumab in the successful management of choroidal metastases secondary to lung and breast cancer unresponsive to systemic therapy: a case series. Eye (Lond) 2014; 28(7): 888-891.

9 Kim M, Kim CH, Koh HJ, Lee SC, Kim SS. Intravitreal bevacizumab for the treatment of choroidal metastasis. Acta Ophthalmol 2014; 92(1): 80-82.

10 FDA approval for Bevacizumab on National Cancer Institute website http://www.cancer.gov/cancertopics/druginfo/ fda-bevacizumab. last viewed 6 January 2015, updated 4 December 2014.

11 Wisniewska-Kruk J, Klaassen I, Vogels IM, Magno AL, Lai CM, Van Noorden CV et al. 'Molecular analysis of blood-retinal barrier loss in the Akimba mouse, a model of advanced diabetic retinopathy'. Exp Eye Res 2014; 122: 123-131.

12 van Lookeren Campagne M, LeCouter J, Yaspan BL, Ye W. 'Mechanisms of age-related macular degeneration and therapeutic opportunities'. J Pathol 2014; 232(2): 151-164. 